\title{
3D-CT imaging processing for qualitative and quantitative analysis of maxillofacial cysts and tumors
}

\section{Processamento de imagens em 3D-TC para análise qualitativa e quantitativa de cistos e tumores maxilo-faciais}

\author{
Marcelo de Gusmão Paraiso Cavalcanti* \\ José Leopoldo Ferreira Antunes**
}

\begin{abstract}
The objective of this study was to evaluate spiral-computed tomography (3D-CT) images of 20 patients presenting with cysts and tumors in the maxillofacial complex, in order to compare the surface and volume techniques of image rendering. The qualitative and quantitative appraisal indicated that the volume technique allowed a more precise and accurate observation than the surface method. On the average, the measurements obtained by means of the 3D volume-rendering technique were $6.28 \%$ higher than those obtained by means of the surface method. The sensitivity of the 3D surface technique was lower than that of the 3D volume technique for all conditions stipulated in the diagnosis and evaluation of lesions. We concluded that the 3D-CT volume rendering technique was more reproducible and sensitive than the 3D-CT surface method, in the diagnosis, treatment planning and evaluation of maxillofacial lesions, especially those with intra-osseous involvement.

UNITERMS: Tomography, X-ray computed; Image processing, computer-assisted; Face; Cysts; Neoplasms.
\end{abstract}

RESUMO: O presente trabalho consiste em um estudo associativo e comparativo entre as técnicas de superfície e volume para a reconstrução de imagens em três dimensões (3D) utilizando tomografia computadorizada (TC). Foram realizadas tomografias computadorizadas em espiral de 20 pacientes com cistos e tumores do complexo maxilo-facial para análise qualitativa e quantitativa, utilizando métodos de superficie e de volume em 3D. A comparação interexaminadores apresentou erro padrão percentual menos elevado para a técnica de volume $(1,94 \%)$ que para a técnica de superficie $(4,38 \%)$, indicando a maior reprodutibilidade do primeiro método. As medidas obtidas pela técnica de volume foram em média $6,28 \%$ mais elevadas que as medidas obtidas pela técnica de superfície. A técnica de volume apresentou sensibilidade mais elevada que a técnica de superficie na identificação das lesões do complexo maxilo-facial. A técnica de volume em 3D-TC, utilizando a metodologia da computação gráfica, apresentou maior reprodutibilidade e sensibilidade para o diagnóstico, planejamento e acompanhamento do tratamento, principalmente das lesões com comprometimento intra-ósseo.

UNITERMOS: Tomografia computadorizada por raios X; Processamento de imagens assistido por computador; Face; Cistos; Neoplasias.

\section{INTRODUCTION}

Current resources of computed tomography (CT) allow reconstructing three-dimensional (3D) images that improve the diagnosis and monitoring of treatments in several maxillofacial pathological conditions s, $^{1,3,4,5,13,14}$. Axial slices obtained from CT are sent to an independent workstation, which utilizes an appropriate hardware and software to generate 3D images ${ }^{1,2,3,4,6,13}$. Those images can be processed by means of different protocols - the 3D surface- and the 3D volume-rendering techniques ${ }^{9}$.

The surface-rendering of 3D images allows the assessment of the surfaces of anatomic struc- tures. Bony structures are associated with light-reflecting surfaces, and mathematical algorithms estimate the surface of voxels, whose segments reflect a higher or lower intensity of light, depending on the location of the observer ${ }^{10}$.

Herman, $\operatorname{Liu}^{7}$ (1977) developed this technique of image processing, which demanded a long interval for the rendering of images. While studying CT lung angiography, Shimizu et al. ${ }^{15}$ (1999) appraised as insufficient the information provided by this technique, because of the absence of image transparency and homogeneous density of the visualized surfaces. Thus, they proposed a technological innovation using multiple colors and trans-

*PhD, Professor, Department of Radiology, School of Dentistry, University of São Paulo, Brazil. Adjunct Professor, Department of Radiology, School of Medicine, University of Iowa, USA.

**PhD, Professor, Department of Social Dentistry, School of Dentistry, University of São Paulo, Brazil. 
Cavalcanti M de GP, Antunes JLF. 3D-CT imaging processing for qualitative and quantitative analysis of maxillofacial cysts and tumors. Pesqui Odontol Bras 2002;16(3):189-194.

parency, which they called the volume-rendering technique. This tool allowed the maintenance of all information regarding the gray scale, and original data could be aggregated from several concurrent CT axial slices. All voxels were preserved, and 3D reconstructed images presented a high standard of visual resolution ${ }^{15}$.

Furthermore, this technique allowed the visualization of the interior aspect of bone and tegument structures, such as intra-osseous cavities, articulations, ligaments, muscles and glands ${ }^{11}$.

Both the 3D surface- and volume-rendering techniques were employed in several studies which assessed different parts of the human body ${ }^{15,17}$. The comparative evaluation of their usefulness for assessing lesions of the maxillofacial complex may improve the diagnosis, surgical planning and monitoring of maxillofacial lesions. Therefore, the present study aimed at a qualitative and quantitative assessment of 3D-CT surface- and volume-rendering of maxillofacial pathological lesions, by means of comparing their results with surgical observations.

\section{MATERIAL AND METHODS}

We assessed the clinical records of 20 patients with different maxillofacial pathological lesions. The diagnoses of their lesions were confirmed by surgical and histopathological examination: dentigerous cyst ( 3 cases), ameloblastoma ( 2 cases), squamous cell carcinoma (4 cases), giant cell cen- tral lesions ( 3 cases), ossifying fibroma (3 cases), keratocyst ( 2 cases), lymphoma ( 2 cases) and adenocarcinoma (1 case).

All patients were examined using spiral CT (Toshiba S/X Press, Toshiba Medical System, Tustin, CA, USA) with the following parameters: $3 \mathrm{~mm}$ of slice thickness, $3 \mathrm{~mm}$ of table feed, $3 \mathrm{~mm}$ of reconstruction interval in 1 second, $120 \mathrm{KVp}$, $150 \mathrm{~mA}$, and Matrix of $512 \times 512$. The original data were sent via network to an independent workstation (DELL PRECISION hardware with WINDOWS NT 420) using the 2.3 version Vitrea ${ }^{\mathrm{TM}}$ software (Vital Images Inc., Plymouth, MN, USA).

Two observers especially trained and calibrated carried out independent interpretations of the 3D-CT surface- and volume-rendered images in a random order. The surgical observation was considered the gold standard for the diagnosis of pathological conditions. For the comparative assessment of both techniques, we used the maximum length of bone destruction. The measurements were carried out using the Vitrea ${ }^{\mathrm{TM}}$ software, in order to compare the precision and validity of both techniques (Figure 1).

The assessment of the precision of a diagnostic tool refers to inter-examiner agreement. The lower the difference between measures obtained by each observer, the higher the precision and reproducibility of the technique. The assessment of the validity of a diagnostic tool refers to its ability in distinguishing cases which present with a certain
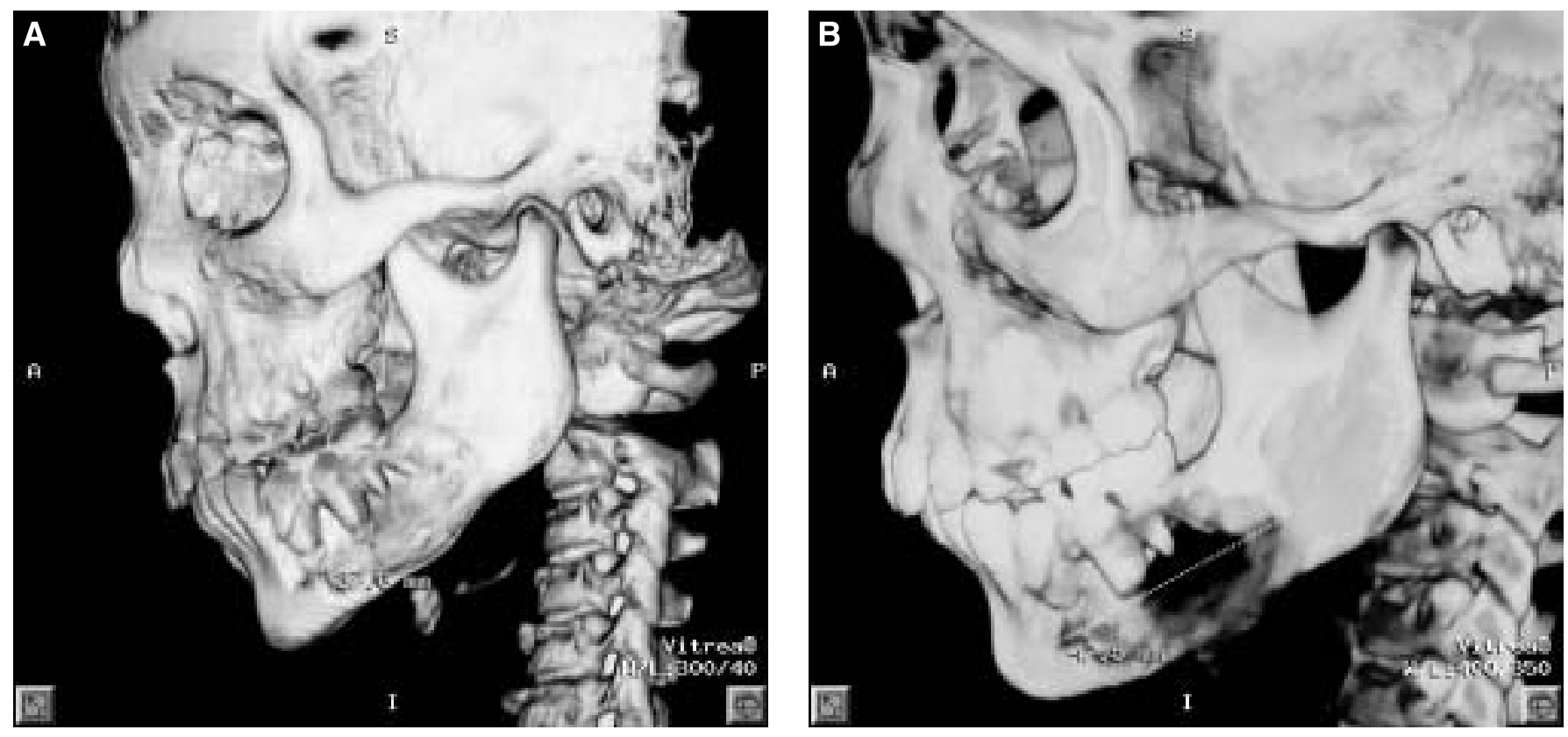

FIGURE 1 - Dentigerous cyst of the mandible. A: 3D-CT surface-rendered image of the lesion indicating 37.6 mm of length destruction. B: 3D-CT volume-rendered image of the same lesion indicating $47.5 \mathrm{~mm}$ of length destruction. 
Cavalcanti M de GP, Antunes JLF. 3D-CT imaging processing for qualitative and quantitative analysis of maxillofacial cysts and tumors. Pesqui Odontol Bras 2002;16(3):189-194.

pathological characteristic from cases which do not $^{16}$. Sensitivity refers to the ability of correctly identifying those who have the disorder. Therefore, we evaluated if both techniques correctly identified the lesions diagnosed by the surgical observation. Specificity is the ability of correctly identifying who does not present with the disorder. Therefore, we also evaluated if both techniques correctly identified the absence of disorders, when disorders were not confirmed in the surgical observation.

We assessed the sensitivity of the surface- and volume-rendering techniques by means of analyzing five different characteristics of lesions: delimitation, location, expansion and destruction of the cortex, and destruction of bone structures. We utilized computer graphics systems to manipulate of the color and transparency of images generated by the 3D-CT volume-rendering technique. The SPSS (Statistical Package for the Social Sciences) program was used to gather the data file and carry out the statistical analysis.

\section{RESULTS}

Table 1 summarizes the assessment of the reproducibility of length measurements obtained by different examiners, for both the 3D-CT surface- and volume-rendering techniques, and it reveals quantitative indications of their standard percentage error. On the average, the volume technique presented a higher inter-examiner agreement, by ranking a lower standard percentage error $(1.94 \%)$ than the surface method $(4.38 \%)$, which indicates its higher precision.

When comparing length measurements obtained by means of the surface and volume techniques of image rendering, we observed a higher standard percentage error $(6.28 \%)$ than the formerly indicated values obtained for inter-examiner comparison of the techniques. Additionally, we noticed that each measure obtained by means of the

TABLE 1 - Assessment of the reproducibility of the surface- and volume-rendering techniques.

\begin{tabular}{l|c|c|c}
\hline \hline \multirow{2}{*}{$\begin{array}{c}\text { Standard } \\
\text { percentage error }\end{array}$} & \multicolumn{2}{|c|}{$\begin{array}{c}\text { Inter-examiner } \\
\text { comparison }\end{array}$} & $\begin{array}{c}\text { Inter-method } \\
\text { comparison }\end{array}$ \\
\cline { 2 - 4 } & $\begin{array}{c}\text { Volume } \\
\text { technique }\end{array}$ & $\begin{array}{c}\text { Surface } \\
\text { technique }\end{array}$ & $\begin{array}{c}\text { Surface } \text { versus } \\
\text { volume }\end{array}$ \\
\hline Average & $1.94 \%$ & $4.38 \%$ & $6.28 \%$ \\
\hline Standard deviation & $2.80 \%$ & $6.12 \%$ & $8.05 \%$ \\
\hline $\begin{array}{l}95 \% \text { confidence } \\
\text { interval }\end{array}$ & 0.64 to & 1.56 to & 3.65 to \\
\hline \hline
\end{tabular}

volume technique was higher than its correspondent value in the surface method.

Table 2 summarizes the assessment of the sensitivity of both techniques, considering the surgical observation as the gold standard for delimitation, location, expansion and destruction of the cortex, and destruction of bone structures. The 3D-CT volume-rendering technique was more sensitive than the 3D-CT surface method for all categories, since its results were more frequently in accordance with the gold standard. The location of lesions was the item with the highest frequency of agreement between 3D-CT images and surgical observations. The detection of bone destruction was the item that evidenced the highest discrepancy between the 3D-CT surface- and 3D-CT volume-rendering techniques.

Both the surface- and the volume-rendering techniques presented specificity equivalent to $100 \%$, with no false-positive observations.

Figure 1 presents 3D-CT surface- and volumerendered images of a patient with a dentigerous cyst in the mandible. The improved delimitation of borders in the 3D-CT volume-rendered image allowed higher precision in the measurement of length. Figure 2 presents $3 \mathrm{D}-\mathrm{CT}$ surface- and volume-rendered images of a patient with a multilocular ameloblastoma. The utilization of transparency and color devices, which were applied in the volume-rendered images, enabled to improve the visualization of limits of the involved structures, allowing the assessment of the extension of the lesion, with its details.

\section{DISCUSSION}

3D-CT volume-rendered images are important tools for pre- and post-surgical examinations of head and neck tumors, and they allow comparisons between the clinical conditions of lesions in different periods, during the follow-up of treatments ${ }^{1,2,3,10,13}$. Udupa et al. ${ }^{17}$ (1991) stated that 3D-CT volume-rendered images resulting from appropriate data pro-

TABLE 2 - Assessment of the sensitivity of the surfaceand volume-rendering techniques.

\begin{tabular}{l|c|c}
\hline \hline \multicolumn{1}{c|}{ Characteristics of lesions } & Surface & Volume \\
\hline Localization & $66.7 \%$ & $100.0 \%$ \\
\hline Delimitation of borders & $61.1 \%$ & $88.0 \%$ \\
\hline Expansion of the cortex & $61.1 \%$ & $94.4 \%$ \\
\hline Destruction of the cortex & $55.5 \%$ & $94.4 \%$ \\
\hline Destruction of bone structures & $38.9 \%$ & $94.4 \%$ \\
\hline \hline
\end{tabular}


Cavalcanti M de GP, Antunes JLF. 3D-CT imaging processing for qualitative and quantitative analysis of maxillofacial cysts and tumors. Pesqui Odontol Bras 2002;16(3):189-194.
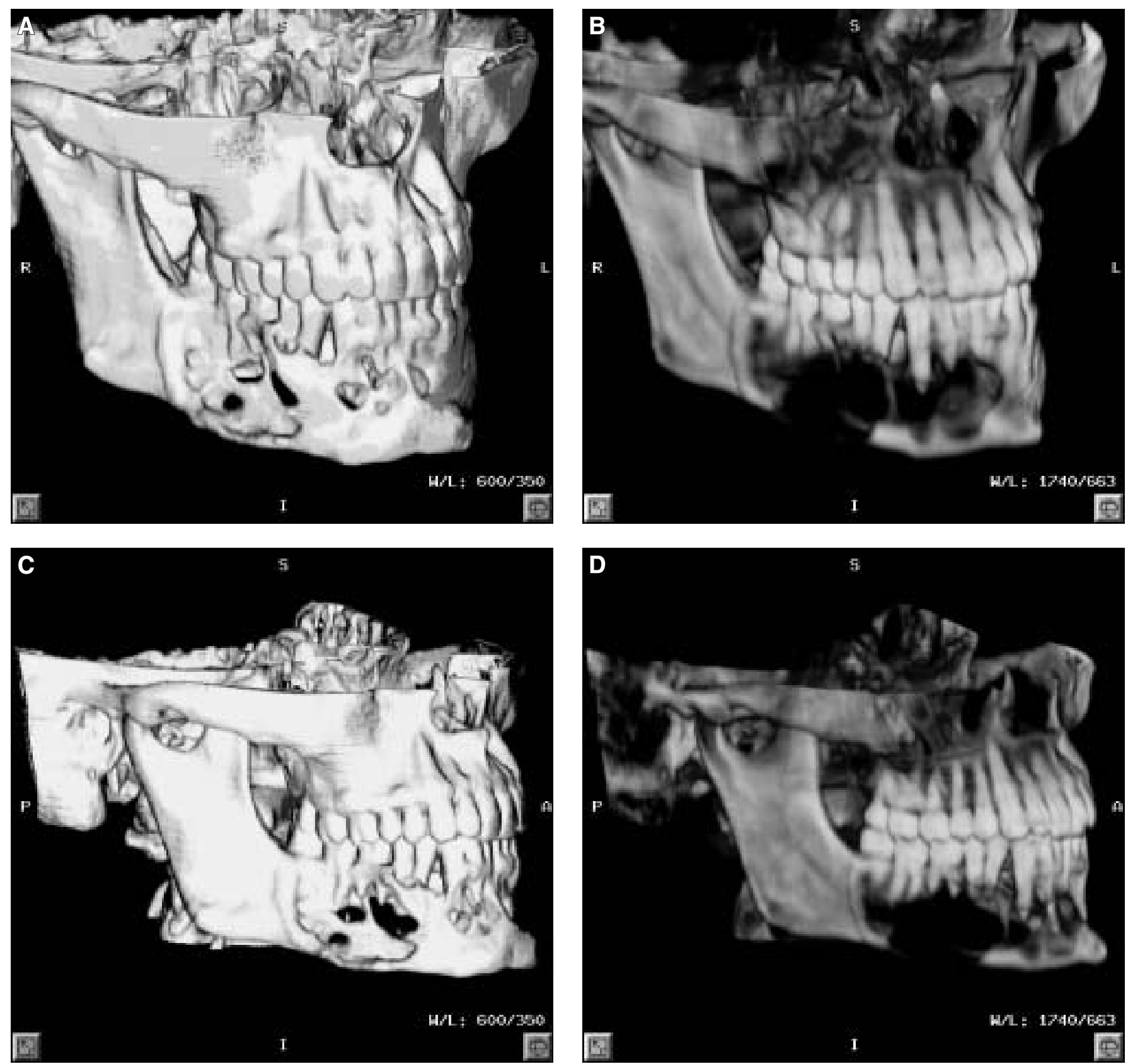

FIGURE 2 - Multilocular ameloblastoma. A and C: 3D-CT surface-rendered images indicating destruction of the buccal and lingual cortex of the mandible. B and D: 3D-CT volume-rendered images indicating destruction of the mandible involving the incisors.

cessing would enable observations equivalent to those obtained by means of the surface method.

Based on our results we think that recent developments of new graphic computational devices aroused a growing interest for further utilization of 3D-CT images. This perception aroused the proposal of comparing the precision and validity of both techniques of 3D-CT image rendering. The 3D volume method was a technical improvement of the 3D surface method, allowing the utilization of color and transparency resources, and a better visualization of anatomical structures. Udupa et al. ${ }^{17}$ (1991) highlighted the fact that not all of the voxels obtained by CT contribute for the rendered 3D images, because during the process of image segmentation some of them are disaggregated. This 
Cavalcanti M de GP, Antunes JLF. 3D-CT imaging processing for qualitative and quantitative analysis of maxillofacial cysts and tumors. Pesqui Odontol Bras 2002;16(3):189-194.

process has the inconvenience of impairing the visualization of images rendered by the surface method. Volume-rendered images, otherwise, allow the preservation of all voxels, which leads to better final 3D image resolution ${ }^{17}$.

Several reports have stated that the 3D-CT surface-rendering technique is an aid to visualization, functioning as a complement to 2D-CT images ${ }^{4,5,6,14}$. However, recent reports have demonstrated the application of 3D-CT volume-rendering technique associated to computer graphics for the analysis of particular pathological lesions. This is due to its specific software package, which is as an important tool for the establishment of the diagnosis ${ }^{1,2,3}$.

In the current study, we found that the 3D volume technique qualitatively improved rendered images, refining their visualization and facilitating the detection of anatomic structures affected by maxillofacial lesions. Transparency and color tools allowed for distinguishing bone in normal and pathological conditions.

Marro et al. ${ }^{12}$ (2000) reported important information demanded for the treatment of an intracranial aneurysm using the volume rendering of 3D-CT images. The utilization of several colors and different levels of brightness and opacity by means of the transparency tool allowed for an improved management of 3D-CT volume-rendered images, segmenting the involved site to evaluate the superposition of anatomical structures. On account of considering all original information from several concurrent CT axial slices, the volume method requires large computational time and storage supply from the workstation, besides a broader skill of examiners to obtain the desired images ${ }^{9}$.

The precision of length measurements obtained by means of the volume technique was better than that of the measurements obtained with the surface method, because of the better visualization of the area involved by the lesion. Figure 1 illustrates the ability of this technique in determining the length of the lesion, due to the utilization of computer graphics tools.

The current evaluation of the volume technique as more precise and sensitive for the diagnosis of lesions in the maxillofacial complex is consistent with the studies of Hooper et al. ${ }^{8}$ (1996) and Marro et al. ${ }^{12}$ (2000). This statement is confirmed by the image presented in Figure 2 - a greater extent of the lesion can be seen in images rendered by the volume technique because of the improved delimitation of its borders. The concurrent utilization of transparency and color resources allowed a better identification of the multilocular ameloblastoma in Figure $2 \mathrm{~B}$ and D than in Figure $2 \mathrm{~A}$ and $\mathrm{C}$, due to an enhanced image of boundaries and limits of the adjacent bone tissue.

The main findings of this study are consistent with recent researches on the 3D volume-rendering technique, which report the more precise and sensitive diagnostic results of this technique when compared to the 3D surface method ${ }^{9,12}$. According to our results, while the volume technique presented an overall sensitivity of $94.2 \%$ for the delimitation of maxillofacial lesions, its location, expansion and destruction of the cortex, and destruction of bone structures, the average related to the surface method ranked only $46.0 \%$. This observation accounted for the higher validity of the volume method, despite the fact that both techniques presented equivalent and satisfactory specificity.

The development of a protocol for the utilization of these techniques in the diagnosis, surgical planning and therapeutic follow-up of maxillofacial lesions may complement previous researches that have evaluated them for other anatomic sites. We have also observed a higher visual resolution of 3D-CT volume-rendered images, which may have contributed for the higher reproducibility and sensitivity of the method.

\section{CONCLUSIONS}

1. Length measurements carried out by means of the 3D-CT volume-rendering technique were more precise than those performed by means of the $3 \mathrm{D}$ surface method.

2. The 3D-CT volume-rendering technique was also more sensitive than the 3D-CT surface method for the diagnosis of lesions in the maxillofacial complex, especially lesions involving intra-osseous anatomical structures.

3. Both techniques presented equivalent and satisfactory specificity. However, 3D-CT volume-rendered images presented higher validity in the current study.

4. The 3D-CT volume-rendered images improved visualization when compared to the $3 \mathrm{D}-\mathrm{CT}$ surface technique. The improvement concerned the location of lesions, the identification of cortex destruction, and the involvement of adjacent anatomical structures.

\section{ACKNOWLEDGMENTS}

Grants from the São Paulo State Research Foundation (FAPESP, 99/10276-4), Brazil. 
Cavalcanti M de GP, Antunes JLF. 3D-CT imaging processing for qualitative and quantitative analysis of maxillofacial cysts and tumors. Pesqui Odontol Bras 2002;16(3):189-194.

\section{REFERENCES}

1. Cavalcanti MGP, Ruprecht A, Vannier MW. Evaluation of an ossifying fibroma using 3D-CT reconstructed images. Dentomaxillofac Radiol 2001;30:342-5.

2. Cavalcanti MGP, Ruprecht A, Quets J. Progression of squamous cell carcinoma evaluated using computer graphics of spiral computed tomography. Dentomaxillofac Radiol 1999;28(3):145-51.

3. Cavalcanti MGP, Ruprecht A, Vannier MW. 3D-CT vascular setting protocol using computer graphics for maxillofacial lesions. Pesqui Odontol Bras 2001;15:229-36.

4. Cavalcanti MGP, Vannier MW. The role of three-dimensional spiral computed tomography in oral metastases. Dentomaxillofac Radiol 1998;27(4):203-8.

5. Eisele DW, Richtsmeier WJ, Graybeal JC. Kock WM, Zinreich SJ. Three-dimensional models for head and neck tumor treatment planning. Laringoscope 1994;104:433-9.

6. Fagelman D, Huang AB. Prospective evaluation of lesions of the mandible and maxilla: findings on multiplanar and three-dimensional CT. Am J Roentgenol 1994;163(3):p.693-8.

7. Herman, G. T., Liu, H. K. Display of three-dimensional information in computed tomography. J Comput Assist Tomogr 1977;1(1):155-60.

8. Hooper KD, Kasales CJ, Eggli KD, Tenhave TR, Belman NM, Potok PS, et al. The impact of 2D versus 3D quantification of tumor bulk determination on current methods of assessing response to treatment. J Comput Assist Tomogr 1996;20(6):930-7.
9. Hooper KD, Iyriboz AT, Neuman JD, Mauger DT, Kasales CJ. Mucosal detail at CT virtual reality: surface versus volume rendering. Radiology 200;214(2:517-22).

10. Kawamata A, Ariji Y, Langlais RP. Three-dimensional computed tomography imaging in dentistry. Dent Clin North Am 2000;44(2):395-410.

11. Lee JS, Jani AB, Pelizzari CA, Haraf DJ, Vokes EE, Weichselbaum RR, et al. Volumetric visualization of head and neck CT data for treatment planning. Int $\mathrm{J}$ Radiat Oncol Biol Phys 1999;44(3):693-703.

12. Marro B, Valery CA, Bitard A, Sahel M, Zouaoui A, Randoux B, et al. Intracranial aneurysm on CTA: demonstration using a transparency volume-rendering technique. J Comput Assist Tomogr 2000;24(1):96-8.

13. Mohairir VM, Fried MP, Vernick DM. Computed-assisted three-dimensional reconstruction of head and neck tumours. Laringoscope 1998;108:1592-8.

14. Ray JR CE, Mafee MF, Friendman M, Tahmoressi CN. Applications of three-dimensional CT imaging in head and neck pathology. Radiol Clin North Am 1993;31(1):181-94.

15. Shimizu T, Yoshikawa S, Uesugi Y, Tabuchi K, Nakata Y, Matsui $\mathrm{R}$, et al. Three-dimensional computed tomographic angiography of pulmonary vessels. Radiat Med 1999;17(2):151-4.

16. Szklo M, Javier-Nieto F. Epidemiology: beyond the basics. Aspen: Gaithersburg, Md; 2000. p. 135.

17. Udupa JK, Hung H, Chuang K. Surface and volume rendering in three-dimensional imaging: a comparison. J Digit Imag 1991;4(3):159-68.

Recebido para publicação em 29/10/01

Enviado para reformulação em 24/05/02

Aceito para publicação em 03/06/02 